\title{
Teaching Digital Literacy: The Outcomes from a
}

\section{Learning Lab}

\author{
T. Carron ${ }^{1,2}$, G. Houzet ${ }^{2,3}$, H. Abed ${ }^{1}$, P. Pernelle ${ }^{2,4}$, P.-J. Lainé ${ }^{2}$ and S. Talbot ${ }^{2}$ \\ 1. Sorbonne Universités, UPMC Univ Paris 06, CNRS, LIP6 UMR 7606, Paris 4 place Jussieu 75005, France \\ 2. e-Team TITAN, Université Savoie Mont Banc, Chambéry 73000, France \\ 3. Lab. IMEP-LAHC, Univ. Savoie Mont-Blanc, Chambéry 73000, France \\ 4. Université de Lyon 1, Lyon 69100, France
}

\begin{abstract}
In this article, we describe the recent developments in higher education relative to the digital outcomes. Between these evolutions, we are witnessing new teaching locations or sites called "learning labs". The aim of this article is to present how the deployment of such a location (sometimes named third places) can offer some new perspectives, modifies the way of teaching and gives some interesting results both from the teachers' point of view (in terms of assessment of knowledge and know-how) and for the learners (in terms of motivation, immersion and exchanges). In a second phase, we will focus on the predominant role that electronics can take in setting up formations, especially around "connected objects” (i.e. communicating devices connected to networks). We will illustrate concretely our idea around an experimental training which has obtained the national label GEN (“Grande Ecole du Numérique”).
\end{abstract}

Key words: IoT (Internet of Things), pedagogical innovation, learning lab, digital literacy.

\section{Introduction}

Digital is an axis that spreads widely and affects everybody at all levels of society. It is inevitably accompanied by theoretical considerations about the teaching of this domain both in the school curriculum but also in the companies with the principle of lifelong learning strategy. Among this thinking, new training venues called "labs" (Learning Lab, Fab lab, Living Lab, Media Lab, Innovation lab, HackerSpace, BioHacklab...) are emerging. Implementation of such a place (also referred to as a third place) responds to a changing society and makes it possible, where traditional teaching is no longer appropriate. Indeed, it offers new perspectives for the teacher (in terms of knowledge and know-how assessment) and changes the learning process for the learners (in terms of motivation, immersion and exchanges) [1].

In this article, we will describe in a first chapter the

Corresponding author: T. Carron, Ph.D., associate professor, research fields: computer science, technology enhanced learning. new ways of teaching. Then we will address a multi-domain transversal view that relies at first step on basic knowledge and tools in electronics with the emergence of IoT connected objects (i.e. communicating devices connected to networks). Finally, we will show a validation of these findings by illustrating their implementation in a pilot training currently deployed at the Institute of Technology of Chambéry in Savoie Mont Blanc University.

\section{New Ways to Teach}

The evolution of the cohorts of students immersed and shaped from the earliest years in digital and hyper connectivity (see Fig. 1) requires changing not only the content of the teachings but also the way to transmit them.

Indeed, students are constantly in demand by many channels of communication (social networks) and (traditional) education seems to be experiencing difficulty in finding its place, ending up as an information channel among others. For this reason, it must stand out with a number of advantages. 


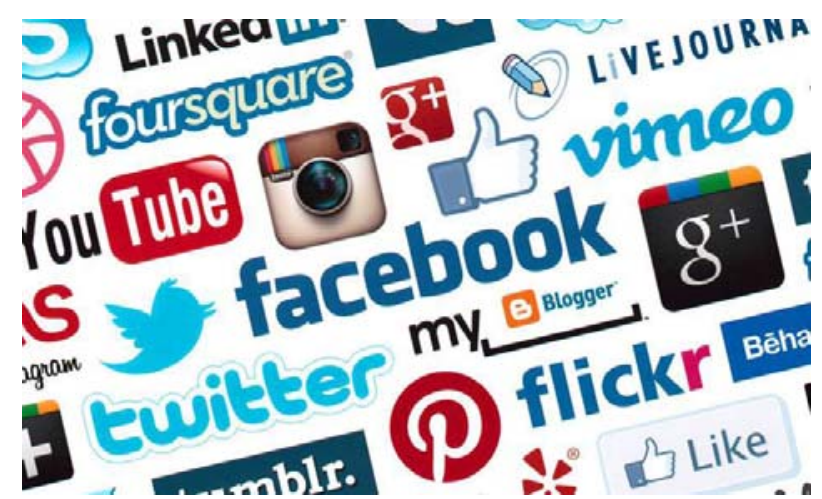

Fig. 1 Hyper-connected students.

To this end, various and deeper thoughts have been carried out and have led to new pedagogical concepts. One of the most convincing at the moment is the so-called "active" pedagogy; experiential learning or Learning by doing approach ${ }^{1}$. This consists of confronting students with the direct application of their knowledge, mostly by carrying out an exercise, a project thanks to placing them in an adapted learning situation [2, 3]: the project-based approach 2 is one of these methods.

Then, it was found that students need to reinvest quickly what they are taught ("What is it for?") [4]: The recommended approach called "Just in Time Teaching" 3 [5], says they are taught what they need when they need it. All this requires rethinking the learning to adapt to these new methods and making the progression systematically compatible with situations of concrete experiments.

A third development concerns motivation and immersion in learning. Serious games' 4 (learning games or game-based learning) approaches give astonishing results on these two aspects [6]. In addition, technological advances have made it possible to use realistic play environments and game-specific features, to adapt existing games or to take up concepts in video games to bring them into the field of education, even by making use of virtual reality for training in an immersive (and safe) experience [7].

\footnotetext{
1 The main concepts are numbered $(\mathbf{0}, \mathbf{2} \ldots)$ to be reminded as reference when they are put into practice in the rest of the article.
}

Not far from these immersive approaches lies a concept called Story Telling $\mathbf{5}$ [8] which can also be applied successfully in teaching. Coming from the field of communication, it consists of playing on the emotional aspects to support the teaching with a narrative process: one tells (and follows) a story.

This has many advantages: first of all, it usually opens up transdisciplinary 6 perspectives, which are globally another point of interest: teaching is often very compartmentalized, whereas today society allows us to easily connect elements of various areas. In this way, teaching can evolve by linking the different aspects, points of view. Another more general advantage of Story Telling is that it creates an object of exchange and discussion with the learners and especially between the learners themselves. This allows us to systematize collaborative approaches $\boldsymbol{\nabla}$. Again, it should be recognized that these methods have been proposed for a long time [9] but are rarely applied in the academic environment: demands for work in pairs are more often linked to constraints in the availability of equipment, places in practical workrooms than to pedagogical choices deliberately oriented towards a collaborative placement of students.

To conclude this overview (which does not claim to be exhaustive) of the possibilities for the evolution of teaching (or in-company training), we will approach online or distance training 8 with the emergence of

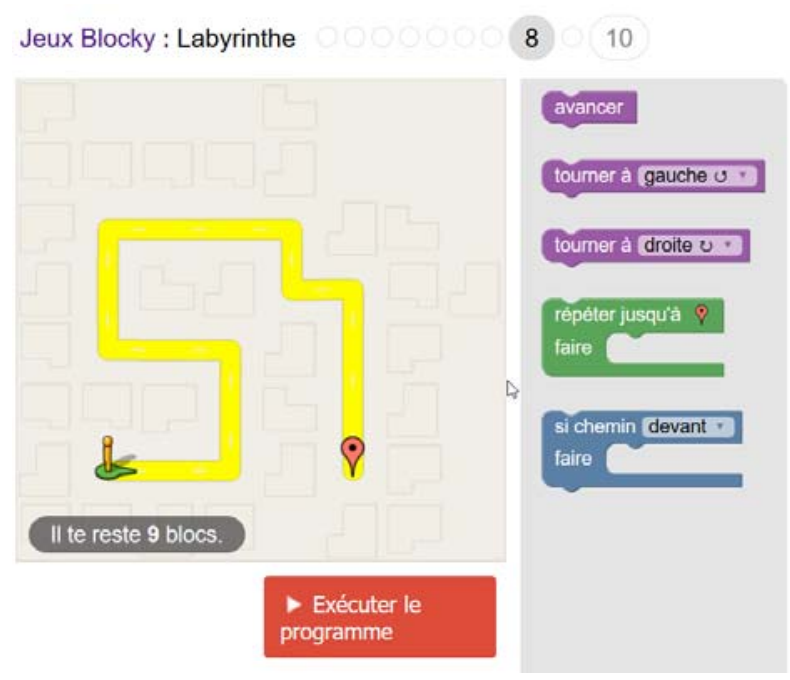

Fig. 2 Example of serious game used for algorithmic. 
videos and associated teaching styles (MOOC/SPOC: Massively Online or Small and Private Open Courses). Indeed, beyond the enthusiasm and the results that are rather debatable (80 to $90 \%$ abandonment on the MOOC [10]), the principle is more interesting in the context that interests us in this article. It relies mainly on uploading videos of the given courses. These videos have, like serious games, the advantage of allowing students to learn at their own speed: in the case of videos, they can even remember or review several times selected sections of the videos that they overlooked during the face-to-face course. Little by little, the development of digital technology brings to light new tools that simplify or enrich these new pedagogical objects by offering the possibility of commenting on them, annotating them, sharing them and, above all, consulting them at any time thanks to, for example, a mobile device (smartphone, tablet). This quite recent trend is called mobile learning. In the same way, the LMS (learning management system) platforms also allow the addition of evaluation tests with the possibility of making automatically a "just in time" $\boldsymbol{\Theta}$ feedback [11, 12].

Now that we have seen the different possibilities, it is necessary to find a central pedagogical content that would be a means of implementing such approaches.

\section{The Object Connected in the Center of the Digital Education}

In parallel with these developments in society, we have also seen significant advances in the field of electronics. Indeed, the emergence of programmable cards based on a free-license microcontroller (type Arduino $^{\mathrm{TM}}$ [1]) has opened the way to an entire ecosystem allowing creating interactive objects based on all kinds of sensors, actuators and end effectors. These elements are not only very accessible (inexpensive) but also very easy to handle, to use.

Designing a working prototype of a connected object thus proves to be possible relatively quickly without requiring a long and complex training step.

Naturally, around the design of this object gravitates a whole set of diverse disciplines that will lead to a complete product. We can cite in the direct line of electronics, aspects related to computing: more complex programming, presentation of information on a website, transformation into digital services, problems related to the network, storage of information, etc. Similarly, it is necessary to situate the object in the economic environment with the study of a potential market, manufacturing costs, and marketing aspects. All these elements relating to management and marketing take their meaning in the realization of such an object and justify pedagogical contributions in these fields. In the same way, communication and conception/design are essential elements that can and must be tackled when realizing such an object.

In summary, we see that the connected object appears as a support/federative project 10 to a whole set of teaching that takes their meaning in a coherent way around such a way of teaching (Fig. 3).

Now that we have determined a central object for
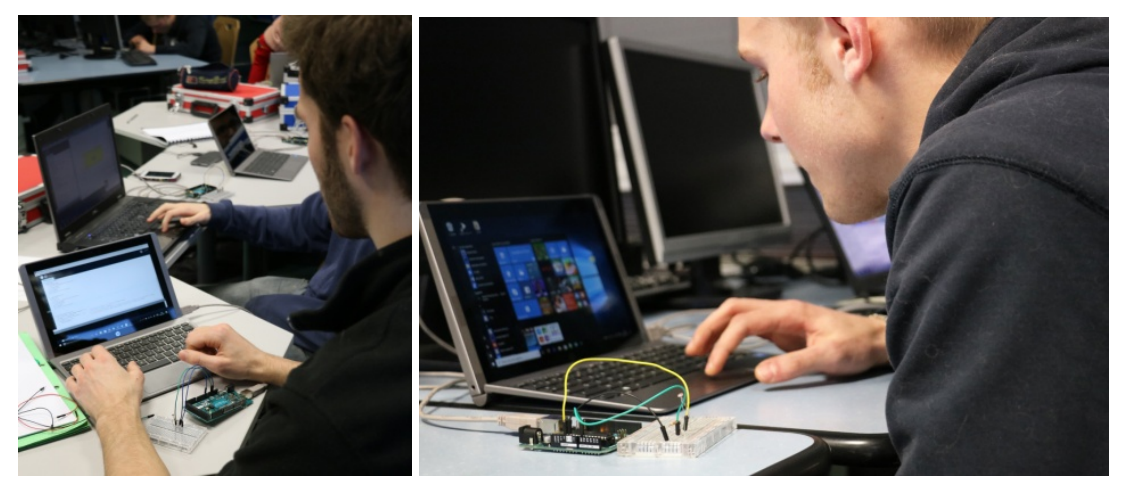

Fig. 3 The object connected to the center of the teachings. 
the contribution of pedagogical content, we will focus in the next chapter on the implementation of an adequate teaching environment. We have given the example of a connected object but it is likely that other concepts might be suitable for other types or targets of teaching.

\section{A New Environment: The Learning Lab}

We have identified several possible ways of adapting education to today's society: the teaching environment must also evolve. Indeed, we can make several remarks: teachers increasingly ask for flexible (reconfigurable) environments, in particular to be able to work in groups and to identify distinct spaces according to the pedagogy put into practice (Fig. 4).

A space of $70 \mathrm{~m}^{2}$ has therefore been reserved and equipped to set up these innovative courses. Conceptually, we identify different (flexible) zones:

- A space "staging of knowledge or know-how" where the teacher can not only transmit but also show concretely (several display spaces, filming/zooming on a live manipulation) 3. It is a space of knowledge but also of sharing and exchanges: the role of the teacher evolves. It can be staged and extended outside by "learning corridors" to share/show/valorize the results and encourage the curiosity from others.

- A “co-working” $\boldsymbol{\nabla}$ and experimentation area (with easily movable furniture) where students manipulate and realize. With a project-based approach 2 , this encourages the learning of transversal skills $\boldsymbol{\bullet}$ (collaboration, interaction, project management, creativity, reflexivity or even meta-cognition). For example, the status of the error must evolve: one experiment and one also understands by mistaking himself $\boldsymbol{\Theta}$.

- An on-line training area with computers equipped with headphones to replay specific courses 8 (self-regulated learning [13]), tutorials, and training with MOOC or serious games 4 .

- A space devoted to creativity 6 with tools (writing pens on windows, giant post-it, 3D printer and pens, technical catalogs...). It is also a demonstration space for giving ideas $\boldsymbol{5}$, capitalization with a view to feeding the previous area (dissemination of results).

\section{Practice: Pilot Training on Connected Objects}

Supported by different national ministries, a training based on these proposals began in January 2017. And 14 students without a diploma were recruited after a positioning test (general understanding, logical sense) in order to ensure their capacity to follow such training.

The 6-month training takes place entirely in the learning lab. Students can position themselves as they want and have digital tablets available for taking notes, photos: it is not uncommon for them to get up to retrieve the precise information directly on a screen or the object being manipulated by the trainer, to take

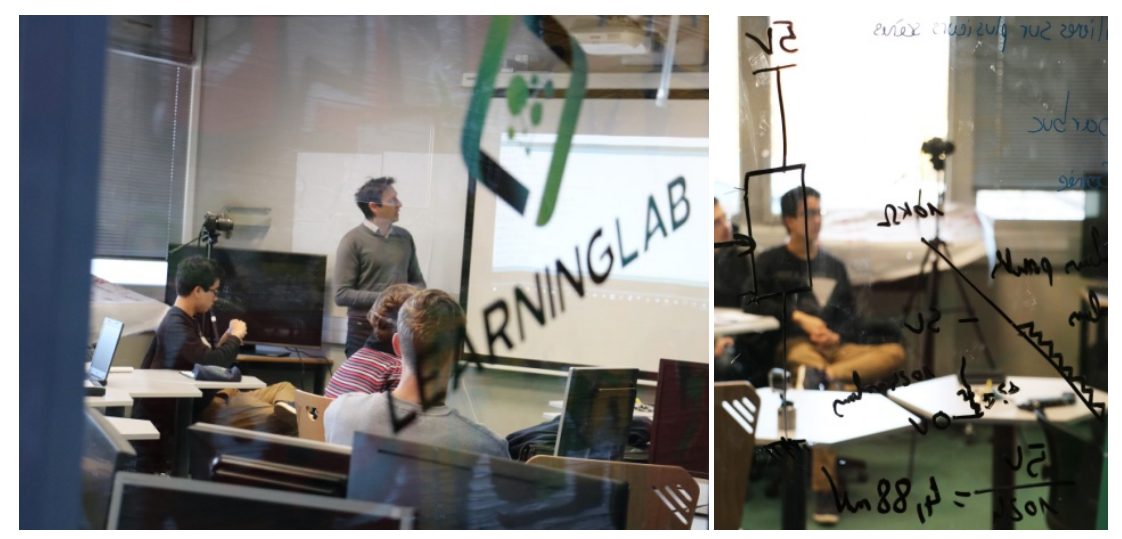

Fig. 4 The learning lab of the Chambéry IUT. 
naturally some pictures or even film with their own device a specific manipulation. They also have at their disposal a briefcase with all the electronics elements $\mathbf{D}$ that support the course for live experiments (at the same time as the teacher). Here, too, collaboration is allowed and cooperation is established $\boldsymbol{\nabla}$.

Some parts of rather theoretical courses (algorithmic bases) are filmed $\mathbf{8}$ and/or some rather tedious (web programming) are put into practice by means of serious games 4 (Fig. 2): they solve puzzles using the concepts of the course: the difficulty is gradual and everyone can progress at his own pace. For the communication and marketing modules, they constitute and manage their virtual company as a game. We find here the Story Telling aspect that was mentioned earlier $\mathbf{6}$.

In terms of (self) assessment, each student receives a skills sheet ("I know, I know how to do") in order to be able to evaluate his or her acquisition and progress (see Table 1). To act accordingly, this principle is called self-regulation [13] and is based on a competency-based approach.

The training is divided into 2 parts: During the first, they learn the concepts, the techniques and the methods $\boldsymbol{O} \boldsymbol{\sigma}$ by realizing all the same connected object (home automation sensor). In the second part, they propose themselves to realize their project of connected object 20 . Teachers go into "coaching/tutoring" mode. The exam consists of presenting their prototype of connected object in front of a jury composed of professionals and academics.

\section{More Descriptive Salient Points}

In this paragraph, we will focus on some specific points that from our point of view gave best results and should be proposed in a more global or regular way or extended.

\section{Agile Methods}

Specific project management highly agile (like scrum method) is taught and used, combined with the concept of learning corridors to expose to the other the on-going projects (see Fig. 7 on the upper side) and encourage question/interest/collaboration. These are a very efficient mean to communicate implicitly and regularly about their work.

\section{Highly Immersive Serious Game with Immediate Skill/Learning Progression}

We also develop ourselves more general serious games with a role play game approach. This federative environment is called Learning Adventure and developed under Unity 3D. These are used to offer the students a mean to validate their knowledge thanks to integrated indicators about the learning progression.

In general, the assessment and acquisition of skills is a complex problem that is generally limited to knowledge assessment [14]. Indeed, it is always possible to define and integrate some mechanisms like MCQ for such assessment. To the best of our knowledge and belief, this is not sufficient to characterize a deep acquisition of a skill, especially concerning know-how. In the context of vocational training, this latter is a much more pertinent element of assessment than intrinsic knowledge. For Learning Adventure, we differentiate two types of assessment: the first one is classical, explicit and quantitative based on MCQ (proposed by non-playable character in the game), the answers are transmitted to a LMS

Table 1 Example of a competency matrix.

\begin{tabular}{|l|l|l|l|l|}
\hline Skills & Content & $\begin{array}{l}\text { “I know” } \\
\text { (a) }\end{array}$ & “I know how to do”(b) & Evaluation \\
\hline Computer science & Web programmation & Web languages & $\begin{array}{l}\text { Building a minimal } \\
\text { HTML acquired } \\
\text { (b) non acquired }\end{array}$ \\
\hline Electronic & Ohm law & $\begin{array}{l}\text { To which correspond U, I } \\
\text { and R }\end{array}$ & $\begin{array}{l}\text { Determine the required } \\
\text { resistance value } \\
\text {. }\end{array}$ & $\begin{array}{l}\text { (a) acquired } \\
\text { (b) acquired }\end{array}$ \\
\hline Communication & Marketing & Goals? & Market analysis & ... \\
\hline
\end{tabular}


platform (see top of Fig. 5) and the results (mark) are send back in the game to calculate and be aware of the current progression (see bottom of Fig. 5: “discovered/acquired").

The second assessment is a semi-explicit one: it is based on some "usage indicators". A usage indicator is the visible result of a number of tasks denoting a business activity, know-how. Such type of indicator aims to provide a simplified but easily understandable representation of a complex activity. For example, we set a "good practice indicator" or a security indicator that might be transversal to several domains (practice of welding, connecting, supplying electric power).
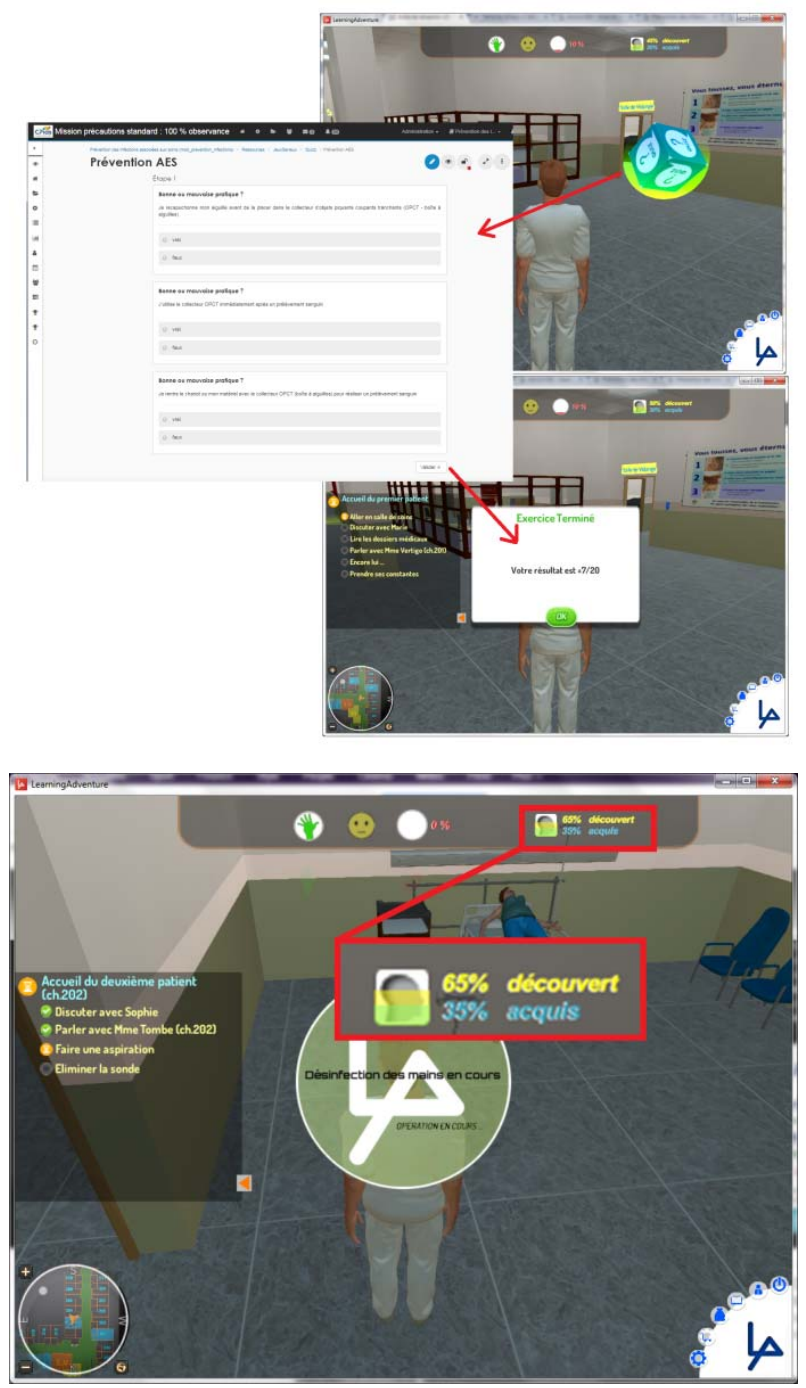

Fig. 5 First part of the assessment in Learning Adventure.
In the next figures, the player/learner can evaluate her/his know-how (by selecting good tools, good
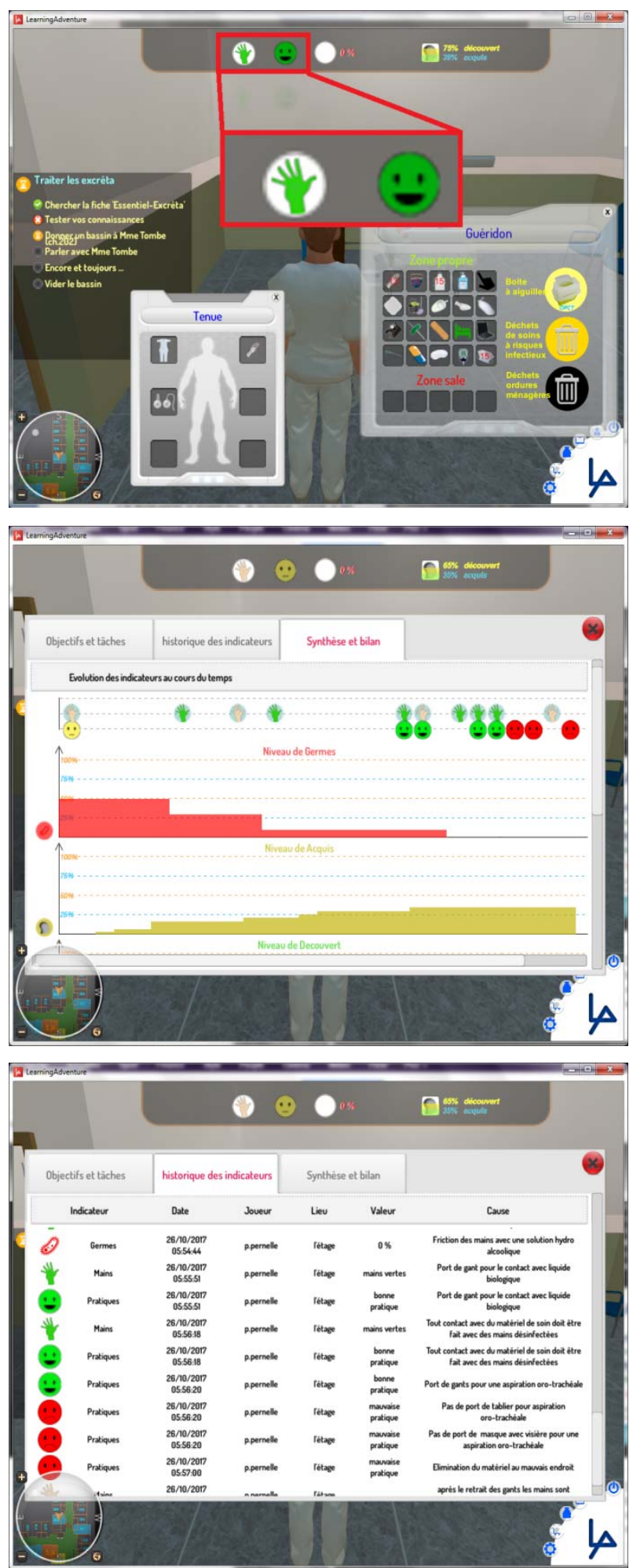

Fig. 6 Know-how indicators process. 
equipment, good raw materials) and identify on a timeline a synthesis and summary of the results: in red, problems are decreasing over time whereas in yellow, the level of acquisition is increasing). In the last figure, the learner can also more precisely identify what was good and what was wrong in her/his practice (see Fig. $6)$.

This is updated in real time during the scenario thanks to an assessment engine. At any moment, the learner (or the instructor) is able to consult the state of these indicators and history of what has been done (when and how).

A multiplayer version is currently tested but was not available for this first session. We also made some mixed reality game [15] coupling such digital learning games with "in real life", concrete interactions around a multi-touch interactive table (see Fig. 7) and around concrete know-how (assembling, connecting soldering, testing) concerning realization of a connected objet (see Fig. 7 IoT design steps: learning corridors, collaboration for soldering and testing, demonstration/proof of concept, overall oral presentation).

\section{Summative Assessment Exported to LMS}

Moreover, over the year, all the results gained in the scenarios played in Learning Adventure are launched and summarized in the LMS "Claroline-Connect" Platform as shown in Fig. 8. This can be considered as a summative assessment. The student will find her/his own results in every domain at the same place (similar to a more classical integrated program approach) [13].

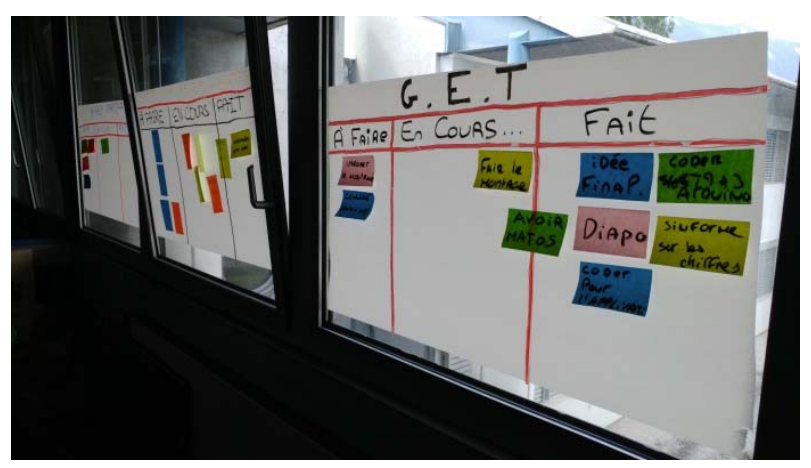

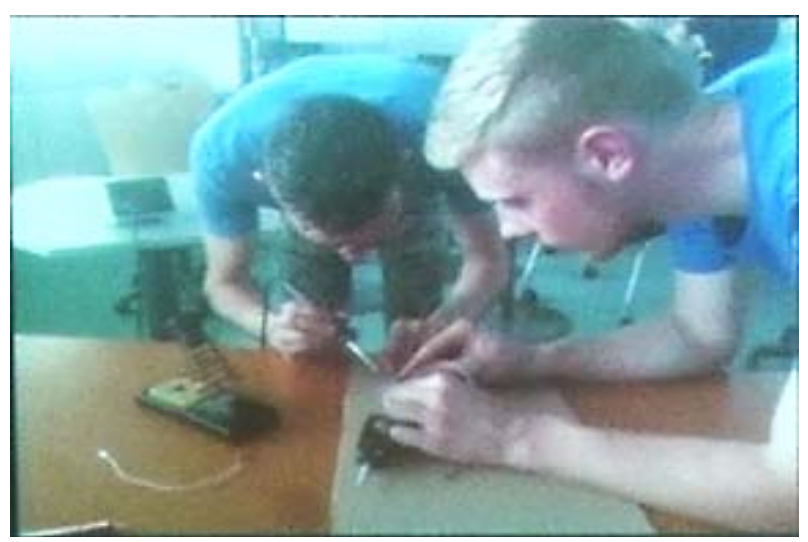
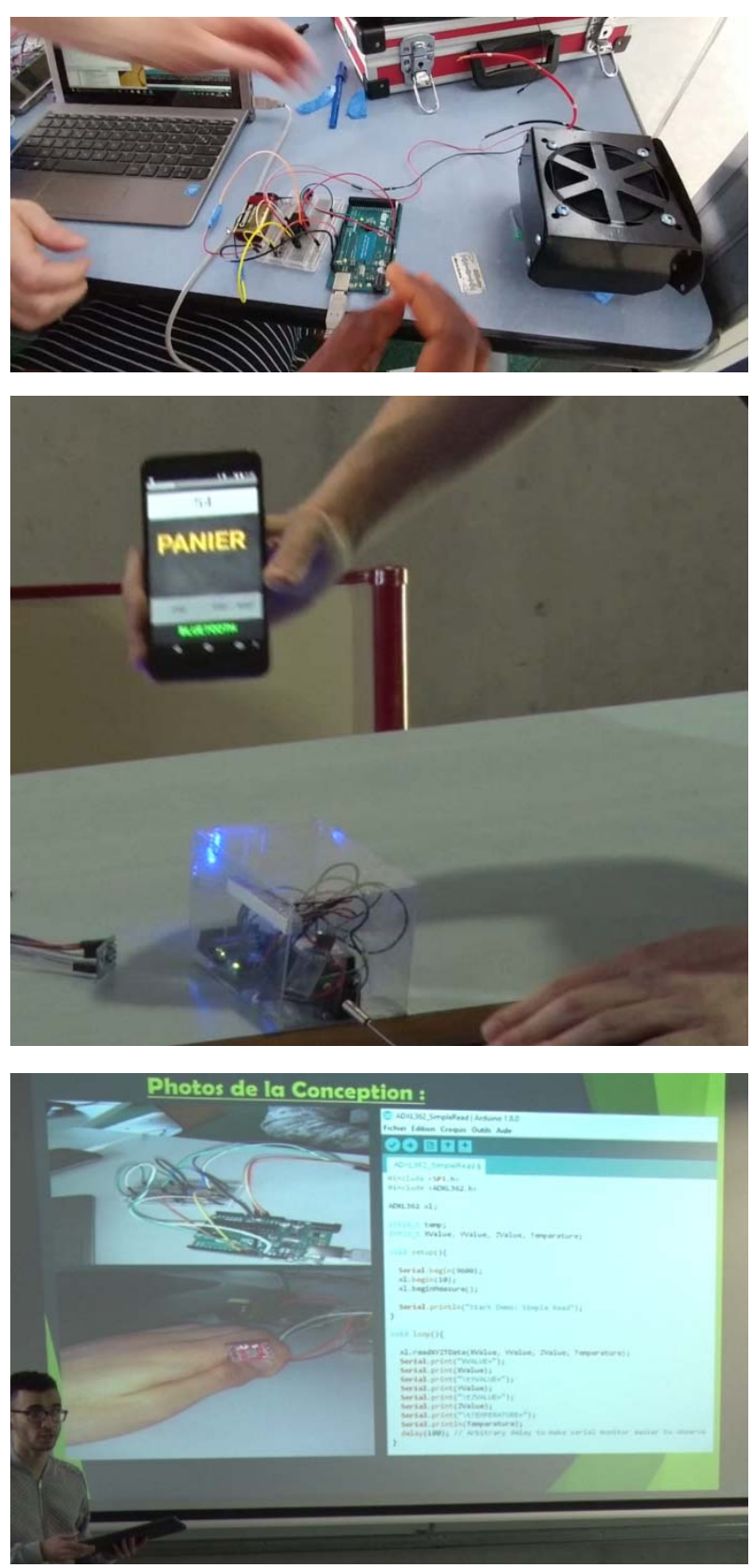

Fig. 7 IoT design: the whole process. 


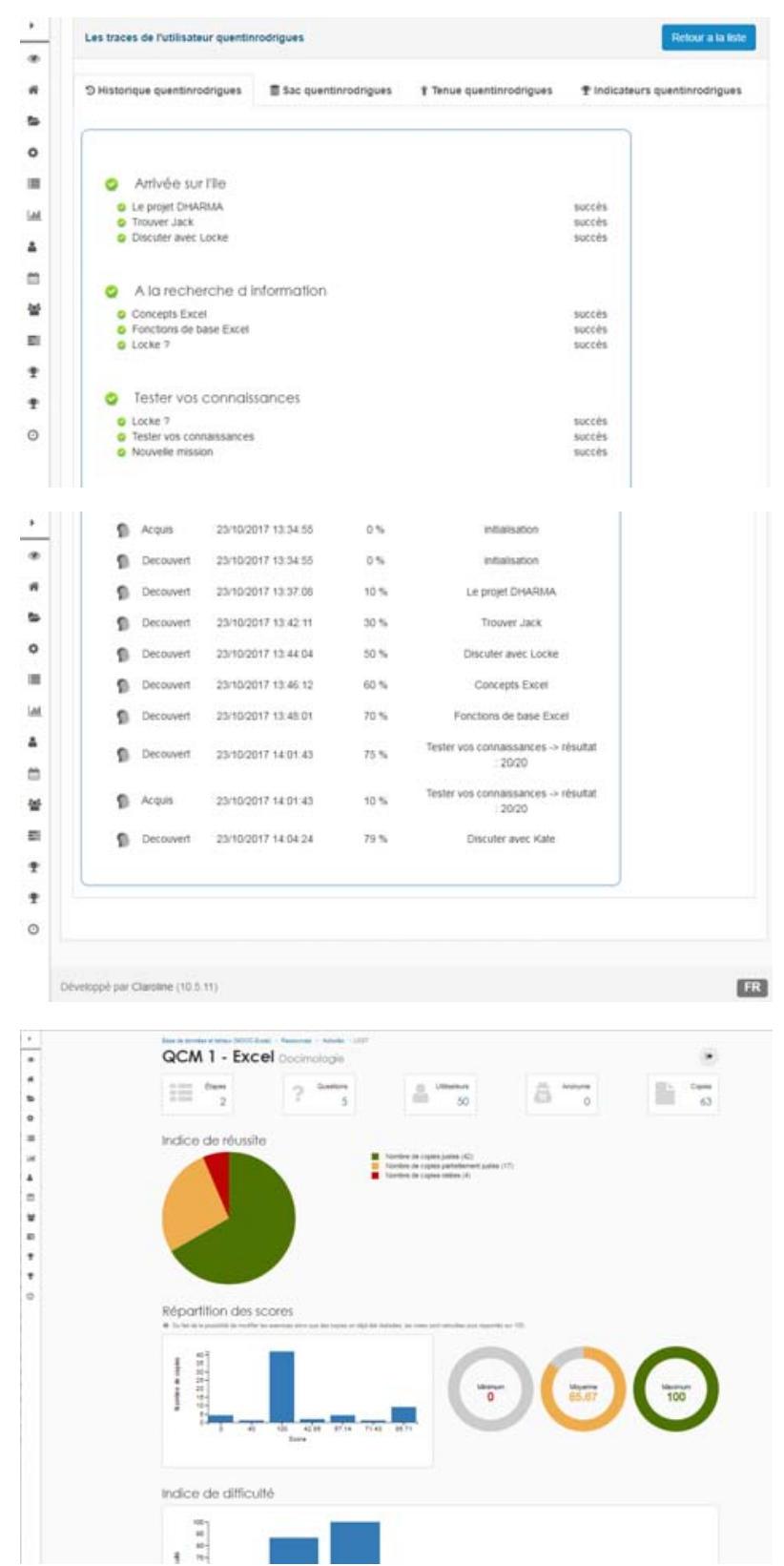

Fig. 8 Summative assessment in LMS.

\section{Results}

The first session of this experimental training is over and some analyses have been done with more stand back.

The sample is quite small but interesting because very heterogeneous. The group of students was unemployed or early school leavers; no condition of diploma or age was requested. All candidates succeeded in the positioning test. They were finally 14 with only two females. The younger was 17 and the older 57 years old. Two of them were foreign people with a rather good knowledge of the French language.

By the way, a new recruitment session is currently alive and amongst the 18 candidates, we have a majority of females. Such innovative training seems then attractive for both males and females.

Concerning the attendance, all followed the whole session without real abandonment, except one student with psychological difficulties: this student did not come to the very last jury where they present their own connected objet ${ }^{2}$.

Two persons chose implicitly to follow some modules (management and marketing) and were not assiduous in others but it was possible that they were already skilled in these domains.

Eight succeeded in getting the university diploma (i.e. present a convincing connected object in front of a professional jury); 13 amongst 14 received a certification of attending the whole training with for some of them, some modules labelled acquired.

It is important to notice that the diploma was not a real objective for most of them: As expected, they felt more like a living experiment: they realized that they succeeded in achieving something from their own, they get self-confidence, they experimented collaboration with persons of different generations, social groups and said to be enchanted with this experiment.

Five of them are back to school (first university level), others (3 and 1) are trying to create their own enterprise and the others are seeking for a job. We hope that presenting their connected object with motivation, concrete proudness, during a recruitment meeting will help them to get a job.

As examples, we can quickly describe some of the modest but convincing realizations:

- A connected (real and distant from house) mail box: when some letters, parcels are put in, a led will

\footnotetext{
${ }^{2}$ We chose not to present the results with tables and percent because the too few number of the sample will lead to not reliable, misunderstanding or even misguided interpretation (female, stranger, aged person).
} 
be lighted on in the house.

- A bracelet to analyze the UVA-UVB rays from the sun on the skin. When a dangerous quantity has been received: a led is light up or a message is sent to the phone to warn the person to put on some sun cream again.

- A basket-ball counter for people playing outside (street playground).

- An add-on device for apartment bicycle in order to control the movement in a virtual world.

\section{Discussion}

We also identify some drawbacks or difficulties: the role of the teacher is evolving: she/he becomes a facilitator to get knowledge more than a provider. As in small classes, the teacher is expected to be able to answer (or find people able to get the answer) in every domain. Some teachers are already used to doing that or like this multi or mixed-disciplinary evolution of their work but for others, it is more difficult. Nevertheless, all teachers were ready to continue for the next session.

In the next session, we will restrain the first part (basic knowledge) and give more time to self-realization (second part). We also continue the principle of self-assessment: the students explain/describe/discover and fill them-selves their (new) skills (knowledge and know-how) and their level of mastering. The teachers will only help them to "structure" this personal description of learning progression and help them to reach metacognition and think about their best aptitude for learning.

From a more technical point of view, we do not focus on specific technologies. Concerning the platforms, we used both MOODLE (for tests with direct feedbacks and for offering pedagogical content) [16] and Claroline Connect (for assessment and serious game orchestration) [12]. A unique and simpler platform is currently developed to try to federate all the types of content (course, video, exercises and serious game) and surt-out to get the student as producer of their own content.

\section{Conclusion}

In this article, we have shown how the evolution of society implies changes in the way of teaching. We can also call it the disruption of digital learning. After identifying a number of paths of thinking, we have shown how to reify them within a particular space called a learning lab and illustrate their implementation in a pilot training around a central objective: realize a connected object. The feedback from these students is very positive: they are very aware of and sensitive to the use of these new practices. From our point of view, most of the first results concerning this sort of instrumented collaborative practices are convincing for such a particular public. Moreover, it seems possible to extend it to other areas, such as computer security or robotics for example. Indeed, in such context, we observe now the emergence of a lot of pedagogical instruments proposed to the teachers: from an external point of view, this work is a try to enable already experienced professionals to feel at home with these tools/methods in a coherent way.

\section{Acknowledgment}

The authors thank the French Ministry of Education and Research and the Auvergne Rhône-Alpes region for their support in the implementation of this innovative training.

\section{References}

[1] Abed, H., Pernelle, P. H., Talbot, S., Kredens, E., and Carron, T. H. 2015. "Teaching Generation Y and Z with Mixed Reality: From Virtual with Serious Game to Real with IoT.” E-Learn 2015: World Conference on E-Learning, Kona, Hawaii, USA.

[2] Hernández-Leo, D., Harrer, A., Dodero, J. M., Asensio-Pérez, J. I., and Burgos, D. 2007. “A Framework for the Conceptualization of Approaches to 'Create-by-Reuse' of Learning Design Solutions." Journal of Universal Computer Science 13 (7): 991-1001.

[3] Dasaratha, V., Rama, E., and Zlotkowski, A. "Learning by Doing: Concepts and Models for Service-Learning in 
Accounting.” Stylus Publishing, LLC, 1998-228.

[4] Hainley, V., and Henderson, J. 2006. "Instructional Design Principles for Serious Games.” MultiLingual 17 (8): 49-52.

[5] Simkins, S., and Maier, M. Just-in-Time Teaching: Across the Disciplines, across the Academy. Stylus Publishing, LLC, 2010-190.

[6] Wilson, K. A., Bedwell, W. L., Lazzara, E. H., Salas, E., Burke, C. S., Estock, J. L., Orvis, K. L., and Conkey, C. 2009. "Relationships between Game Attributes and Learning Outcomes: Review and Research Proposals." Sim. \& Gaming 40 (2): 217-66.

[7] Abed, H., Pernelle, P. H., Carron, T. H., Ben Amar, C. H., Kechiche, M., amd Baert, P. 2015. "Serious Game Framework Confronted with Specificities of Industrial Training: Application to Steel Industry." The 9th European Conference on Games Based Learning, ECGBL 2015, Steinkjer, Norway.

[8] Michael, F., Connelly, D., and Clandinin, J. 1990. "Stories of Experience and Narrative Inquiry." Educational Researcher 19 (5): 2-14.

[9] Vygotsky, L. S. 1978. Mind and Society: The Development of Higher Psychological Processes. Cambridge, MA: Harvard University Press, Published Originally in Russian in 1930.

[10] Gütl, C., Rizzardini, R. H., Chang, V., and Morales, M. 2014. "Attrition in MOOC: Lessons Learned from
Drop-out Students', In L. Uden, J. Sinclair, Y.-H. Tao, and D. Liberano (Eds.), Proceedings of Third International Workshop on Learning Technology for Education in Cloud, 37-48. Cham, Switzerland.

[11] Zaïane, and Luo, J. 2001. “Towards Evaluating Learners' Behaviour in a Web-Based Distance Learning Environment." In Proceedings of IEEE International Conference on Advanced Learning Technologies, Madison, USA, 357-60.

[12] https://www.claroline.net/EN/index.html: The Claroline-Connect LMS.

[13] Zimmerman, B. J. 1990. "Self-regulated Learning and Academic Achievement: An Overview.” Educational Psychologist 25: 3-17.

[14] Gress, C. L. Z., Fior, M., Hadwin, A. F., and Winne, P. H. "Measurement and Assessment in Computer-Supported Collaborative Learning." Computers in Human Behavior, Advancing Educational Research on Computer-Supported Collaborative Learning (CSCL) through the Use of Study CSCL Tools 26 (5): 806-14.

[15] Marty, J. C. H., Carron, T. H., Pernelle, P. H., Talbot, S., and Houzet, G. 2015. "Mixed Reality Games." International Journal of Game-Based Learning (IJGBL) 5 (1): 32-47. I. Patrick Felicia (Waterford Institute of Technology (Ed.), IGI-Global (ed.), (Patrick Felicia).

[16] https://moodle.org/?lang=en: The moodle LMS. 